\title{
Treatment-related toxicities of apatinib in solid tumors: a meta- analysis
}

\author{
Ling Peng ${ }^{1}$, Xianghua Ye $^{2}$, Yun Hong ${ }^{3}$, Junyan Zhang ${ }^{4}$, Yongquan Dong ${ }^{5}$ and Qiong \\ Zhao ${ }^{1}$ \\ ${ }^{1}$ Department of Thoracic Oncology, The First Affiliated Hospital, School of Medicine, Zhejiang University, Hangzhou, Zhejiang \\ Province, China \\ ${ }^{2}$ Department of Radiotherapy, The First Affiliated Hospital, School of Medicine, Zhejiang University, Hangzhou, Zhejiang \\ Province, China \\ ${ }^{3}$ Department of Pharmacy, The First Affiliated Hospital, School of Medicine, Zhejiang University, Hangzhou, Zhejiang \\ Province, China \\ ${ }^{4}$ Bothwin Clinical Study Consultant, Bellevue, WA, USA \\ ${ }^{5}$ Department of Respiratory Disease, Yinzhou No.2 Hospital, Ningbo, Zhejiang Province, China \\ Correspondence to: Qiong Zhao, email: zhaoqiong@zju.edu.cn \\ Keywords: apatinib; hypertension; proteinuria; hand-foot-syndrome; meta-analysis \\ Received: July 19, 2017 Accepted: November 03, 2017 Epub: January 13, 2018 Published: August 14, 2018
}

Copyright: Peng et al. This is an open-access article distributed under the terms of the Creative Commons Attribution License 3.0 (CC BY 3.0), which permits unrestricted use, distribution, and reproduction in any medium, provided the original author and source are credited.

\section{ABSTRACT}

Background: Apatinib is a novel small molecular drug targeting vascular endothelial growth factor receptor-2 (VEGFR-2), which is being studied in multiple tumor types. We performed a meta-analysis to quantify the overall incidence and risk of hypertension, proteinuria, and hand-foot-syndrome (HFS) in cancer patients receiving apatinib.

Results: Altogether, 820 cancer patients from 7 prospective trials were included for the meta-analysis. The incidences of all-grade and high-grade hypertension were $45.4 \%$ and $9.7 \%$. The incidences of all-grade and high-grade proteinuria were $45.1 \%$ and $3.7 \%$. The incidences of all-grade and high-grade HFS were $35.9 \%$ and $8.6 \%$. The RRs of all-grade hypertension, proteinuria and HFS of apatinib compared to placebo were increased (hypertension, $R R=6.53$; proteinuria, $R R=2.62$, and HFS, $R R=$ 11.45). The RRs of developing high-grade hypertension and HFS were substantially higher than that of placebo (hypertension, RR = 7.73; HFS, RR = 7.23), but not for proteinuria ( $R R=2.56,95 \%$ CI: 0.57-11.52).

Materials and Methods: Prospective phase II and III clinical trials of cancer patients receiving apatinib were searched and included. Summary incidences, relative risk (RR), and $95 \%$ confidence intervals (CI) were calculated by using either fixed or random effects models according to the heterogeneity of the studies.

Conclusions: Apatinib is generally well tolerated, and associated with increased risks of all-grade hypertension, proteinuria and HFS, and high-grade hypertension and HFS, but not high-grade proteinuria.

\section{INTRODUCTION}

Apatinib (YN968D1) is a potent small molecule inhibitor of vascular endothelial growth factor receptor-2 (VEGFR-2, Flk-1/KDR) and RET (rearranged during transfection) [1]. Although apatinib shares target receptors with other antiangiogenic drugs, it is highly selective. It is approved as third-line treatment for gastric cancer by Chinese Food and Drug Administration in 2014, based on a multi-center, randomized, phase III trial comparing apatinib $850 \mathrm{mg}$ once daily (QD) versus placebo [2]. The results of the study found that overall survival (OS) was increased for patients receiving apatinib compared with placebo (6.5 vs. 4.7 months, $P=0.0149$ ). Currently, 
apatinib is undergoing clinical trials as single agent and in combination with chemotherapy or immunotherapy for treatment of other types of cancer, such as lung cancer, colorectal cancer, esophageal cancer.

Apatinib is almost free of the classical toxicities of cytotoxic chemotherapy, but other side effects such as hypertension, proteinuria and hand-foot-syndrome, can lead to decreased quality of life (QoL) or interruptions of treatment. The overall incidences and RRs of the most common adverse events of apatinib have not been systematically reviewed. It allows for clinical consideration of specific therapies based on efficacy and toxicity profiles. Therefore, we conducted this metaanalysis to quantify the incidence and relative risk of the three most toxicities (hypertension, proteinuria and handfoot-syndrome) among cancer patients receiving apatinib.

\section{RESULTS}

\section{Study selection and characteristics}

Our comprehensive search of the literature revealed 81 potentially relevant records. After screening of the study titles and abstracts 56 studies were excluded, as those were not prospective trials. After text review 20 more studies were excluded for not meeting the inclusion criteria. Five studies met the inclusion criteria and data were extracted. Among the 34 abstracts published in ASCO meetings, 2 abstracts were identified. Altogether, 7 primary studies comprising 820 patients were included for analysis (Figure 1). The baseline information of the 7 primary studies were shown in Table 1 , including 1 randomized controlled trials (RCTs) and 6 phase II clinical trials. Underlying malignancies include gastric cancer (2 trials) $[2,3]$, lung cancer (2 trials) $[4,5]$, breast cancer (2 trials) [6, 7] and hepatocellular carcinoma (1 trial) [8]. The sample size ranged from 33 to 267 patients (median, 121 patients). The studies were published between 2012 and 2017, and all the included studies were performed in China. For calculation of the RRs, 3 RCTs were pooled [2-4]. The meta-analysis adheres to the guidelines of the Preferred Reporting Items for Systematic review and Meta-Analyses (PRISMA) statement [9].

\section{Incidence of hypertension, proteinuria and HFS}

The results of the incidences of hypertension, proteinuria and HFS were shown in Figure 2 and Figure 3. A total of 820 patients from 7 trials were included for analysis of incidence. The summary incidence of all-grade and all-grade hypertension was 45.4\% (95\% CI: 38.8 $53.0 \%$ ) and $9.7 \%$ (95\% CI: 5.7-16.7\%) using a random effects model, respectively. Inter-study heterogeneity $I^{2}$ statistics were $98.3 \%$ for all grade hypertension $(P<$ $0.001), 96.1 \%$ for high-grade hypertension $(P<0.001)$, $96.5 \%$ for all-grade proteinuria $(P<0.001), 87.4 \%$ for high-grade proteinuria $(P<0.001), 99.0 \%$ for allgrade HFS $(P<0.001)$, and $80.1 \%$ for high-grade HFS $(P<0.001)$, respectively. No statistically significant subgroup difference was identified in terms of dose $(\geq 750$ mg QD vs $<750 \mathrm{mg}$ QD, Figure 2) or clinical trial type (RCT vs non-randomized trial, Figure 3).

\section{Relative risk of hypertension, proteinuria and HFS}

We determined the relative risks (RRs) of treatmentrelated toxicities compared with control arm. In the included studies, all control arms were placebo. The pooled RR showed that apatinib increased the risk of developing all-grade and high-grade hypertension with a RR of 6.53 (95\% CI: $3.63-11.73, I^{2}=0.0 \%, P=0.774$ ), and 7.73 (95\% CI: $1.50-39.90, I^{2}=0.0 \%, P=0.918$ ), using a fixed effects model, respectively (Figure 4). The $\mathrm{RR}$ of HFS was also increased for all-grade $(\mathrm{RR}=11.45$, 95\% CI: 4.76-22.55, $\left.I^{2}=0.0 \%, P=0.877\right)$ and high-grade $\left(\mathrm{RR}=7.23,95 \%\right.$ CI: $\left.1.74-30.01, I^{2}=0.0 \%, P=0.707\right)$. However, apatinib was associated with increased risk of all-grade proteinuria $(\mathrm{RR}=11.45,95 \% \mathrm{CI}: 4.76-22.55$, $\left.I^{2}=0.0 \%, P=0.819\right)$ but not high-grade proteinuria $(\mathrm{RR}=$ $2.56,95 \%$ CI: $\left.0.57-11.52, I^{2}=0.0 \%, P=0.658\right)$.

\section{Sensitivity analysis}

Sensitivity analysis was performed to test the robustness and stability of our results. The significance estimate of pooled results was not significantly influenced by omitting any single study (Figure 5).

\section{Publication bias}

Seven studies reporting all-grade and high-grade hypertension yielded an Egger's test score of $P=0.405$ and $P=0.383$, respectively. No evidence of publication bias was detected for the incidence of all-grade and highgrade proteinuria of this study $(P=0.570$ and $P=0.054$, respectively). The Egger's test scores for all-grade and high-grade proteinuria were $P=0.826$ and $P=0.538$, respectively.

\section{DISCUSSION}

VEGF signaling pathway plays an important role in the angiogenic process of cancer. VEGFR-2 is autophosphorylated when stimulated by VEGF, which is the most pro-angiogenic effect [10]. VEGFR-2 inhibitors have been developed, including receptor-specific antibodies and tyrosine kinase inhibitors. Among them, apatinib is a selectively inhibitor which targets VEGFR-2 and inhibits c-Kit and c-Src tyrosine kinases. It is approved by Chinese FDA in 2014 for the use in third-line treatment with gastric cancer patients who progressed after second-line 
Table 1: Main characteristics and results of the eligible studies

\begin{tabular}{|c|c|c|c|c|c|c|c|c|c|c|c|c|c|c|c|c|c|c|c|}
\hline \multirow{2}{*}{$\begin{array}{l}\text { Year } \\
2017\end{array}$} & \multirow{2}{*}{$\begin{array}{c}\text { Study } \\
\text { Wang [5] }\end{array}$} & \multirow{2}{*}{$\begin{array}{c}\text { Phase } \\
2\end{array}$} & \multirow{2}{*}{$\begin{array}{c}\text { Research } \\
\text { Single arm }\end{array}$} & \multirow{2}{*}{$\begin{array}{c}\begin{array}{c}\text { Cancer } \\
\text { type }\end{array} \\
\text { NSCLC }\end{array}$} & \multirow{2}{*}{$\begin{array}{l}\text { Source } \\
\text { ASCO }\end{array}$} & \multirow{2}{*}{$\begin{array}{c}\text { Treatment Arm } \\
\text { Apatinib } 250 \mathrm{mg} \text { QD }\end{array}$} & \multicolumn{2}{|c|}{$\begin{array}{l}\text { Hypertension } \\
\text { all-grade }\end{array}$} & \multicolumn{2}{|c|}{$\begin{array}{c}\text { Hypertension } \\
\text { high-grade }\end{array}$} & \multicolumn{2}{|c|}{$\begin{array}{l}\text { Proteinuria } \\
\text { all-grade }\end{array}$} & \multicolumn{2}{|c|}{$\begin{array}{l}\text { Proteinuria } \\
\text { high-grade }\end{array}$} & \multicolumn{2}{|c|}{$\begin{array}{c}\text { HFS all- } \\
\text { grade }\end{array}$} & \multicolumn{2}{|c|}{$\begin{array}{l}\text { HFS high- } \\
\text { grade }\end{array}$} & \multirow{2}{*}{$\frac{\text { Patients }}{33}$} \\
\hline & & & & & & & 10 & $33.3 \%$ & 0 & $0.0 \%$ & 8 & $24.2 \%$ & 0 & $0.0 \%$ & 5 & $15.2 \%$ & 0 & $0.0 \%$ & \\
\hline \multirow[t]{2}{*}{2016} & $\operatorname{Li}[2]$ & 3 & $\mathrm{RCT}$ & Gastric & Pubmed & Apatinib $850 \mathrm{mg}$ QD & 62 & $35.2 \%$ & 8 & $4.5 \%$ & 84 & $47.7 \%$ & 4 & $2.3 \%$ & 49 & $27.8 \%$ & 15 & $8.5 \%$ & 176 \\
\hline & & & & & & Placebo & 5 & $5.5 \%$ & 0 & $0.0 \%$ & 15 & $16.5 \%$ & 0 & $0.0 \%$ & 2 & $2.2 \%$ & 0 & $0.0 \%$ & 91 \\
\hline \multirow[t]{2}{*}{2014} & Qin [8] & 2 & $\begin{array}{l}\text { Parallel } \\
\text { arm }\end{array}$ & $\mathrm{HCC}$ & $\mathrm{ASCO}$ & Apatinib $850 \mathrm{mg}$ QD & 35 & $50.0 \%$ & 2 & $2.9 \%$ & 32 & $45.7 \%$ & 1 & $1.4 \%$ & 29 & $41.4 \%$ & 4 & $5.7 \%$ & 70 \\
\hline & & & & & & Apatinib $750 \mathrm{mg}$ QD & 25 & $49.0 \%$ & 7 & $13.7 \%$ & 22 & $43.1 \%$ & 2 & $3.9 \%$ & 15 & $29.4 \%$ & 4 & $7.8 \%$ & 51 \\
\hline \multirow[t]{2}{*}{2014} & Hu [7] & 2 & $\begin{array}{l}\text { Parallel } \\
\text { arm }\end{array}$ & TNBC & Pubmed & Apatinib $750 \mathrm{mg}$ QD & 15 & $60.0 \%$ & 9 & $36.0 \%$ & 16 & $64.0 \%$ & 1 & $4.0 \%$ & 14 & $56.0 \%$ & 0 & $0.0 \%$ & 25 \\
\hline & & & & & & Apatinib $500 \mathrm{mg}$ QD & 38 & $64.4 \%$ & 7 & $11.9 \%$ & 31 & $52.6 \%$ & 8 & $13.6 \%$ & 14 & $56.0 \%$ & 6 & $24.0 \%$ & 59 \\
\hline 2014 & Hu [6] & 2 & Single arm & $\begin{array}{l}\text { Non } \\
\text { TNBC }\end{array}$ & Pubmed & Apatinib $500 \mathrm{mg}$ QD & 16 & $42.1 \%$ & 8 & $21.1 \%$ & 20 & $52.6 \%$ & 2 & $5.3 \%$ & 20 & $52.6 \%$ & 4 & $10.5 \%$ & 38 \\
\hline \multirow[t]{3}{*}{2013} & $\operatorname{Li}[3]$ & 2 & $\mathrm{RCT}$ & Gastric & Pubmed & Apatinib $850 \mathrm{mg}$ QD & 19 & $40.4 \%$ & 4 & $8.5 \%$ & 13 & $26.7 \%$ & 1 & $2.1 \%$ & 12 & $25.5 \%$ & 2 & $4.3 \%$ & 47 \\
\hline & & & & & & Apatinib $425 \mathrm{mg}$ BID & 18 & $39.1 \%$ & 5 & $10.9 \%$ & 16 & $34.8 \%$ & 2 & $4.3 \%$ & 21 & $45.7 \%$ & 6 & $13.0 \%$ & 46 \\
\hline & & & & & & Placebo & 2 & $4.2 \%$ & 0 & $0.0 \%$ & 6 & $12.5 \%$ & 0 & $0.0 \%$ & 2 & $4.2 \%$ & 1 & $2.1 \%$ & 48 \\
\hline \multirow[t]{2}{*}{2012} & Zhang [4] & 2 & RCT & NSCLC & ASCO & Apatinib $750 \mathrm{mg}$ QD & 42 & $46.2 \%$ & 4 & $4.4 \%$ & 46 & $50.6 \%$ & 2 & $2.2 \%$ & 30 & $33.0 \%$ & 4 & $4.4 \%$ & 91 \\
\hline & & & & & & Placebo & 4 & $8.9 \%$ & 0 & $0.0 \%$ & 10 & $22.2 \%$ & 1 & $2.2 \%$ & 1 & $2.2 \%$ & 0 & $0.0 \%$ & 45 \\
\hline
\end{tabular}

Summary table of studies included in the meta-analysis. Abbreviations: CI, confidence interval; NR, not reported.

chemotherapy. Its application in other cancer types is also under clinical investigation.

Apatinib is generally well tolerated. However, drugrelated toxicities and adverse effects also developed, which are manageable. The major non-hematological adverse effects reported of this drug are hypertension, proteinuria, and HFS, but incidences vary substantially among clinical trials. Management include dose reduction, interruption, or termination of the drug. The time to onset of in the hypertension, proteinuria, and HFS apatinib groups was within 2 to 3 weeks. Due to the small molecule nature of apatinib, the time to resolution of above mentioned side effects was faster than those of bevacizumab. Of note, supportive treatment, which could have contributed to resolution of high-grade AEs could be a confounding factor for time to resolution of AEs.

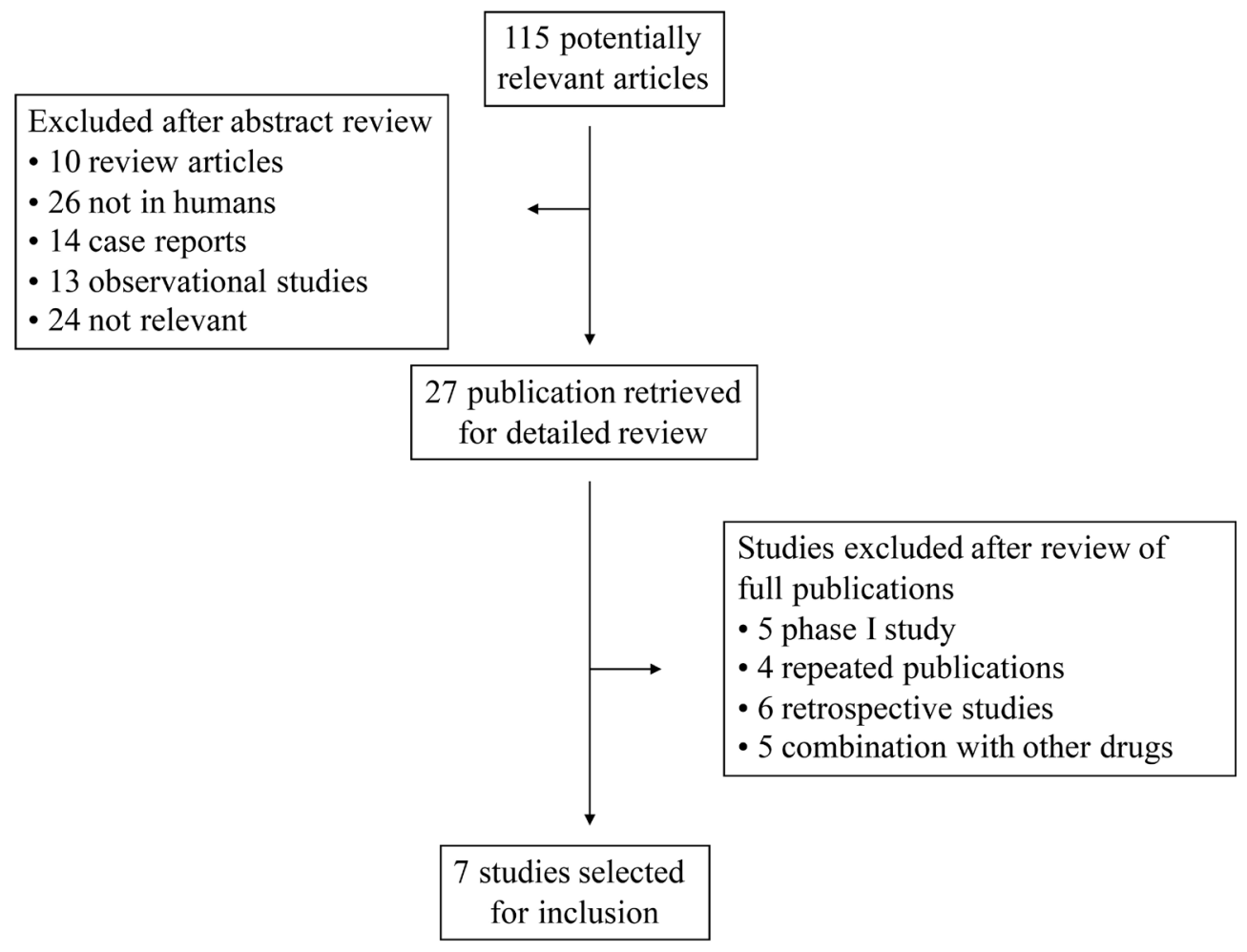

Figure 1: Selection process for the trials included in the meta-analysis. 
The purpose of this study is to quantify the incidences and relative risks of three common toxicities of hypertension, proteinuria and HFS in cancer patients receiving apatinib. This meta-analysis combined 7 studies including 1 phase III trials and 6 phase II trials. The results demonstrated that apatinib is associated with increased

A

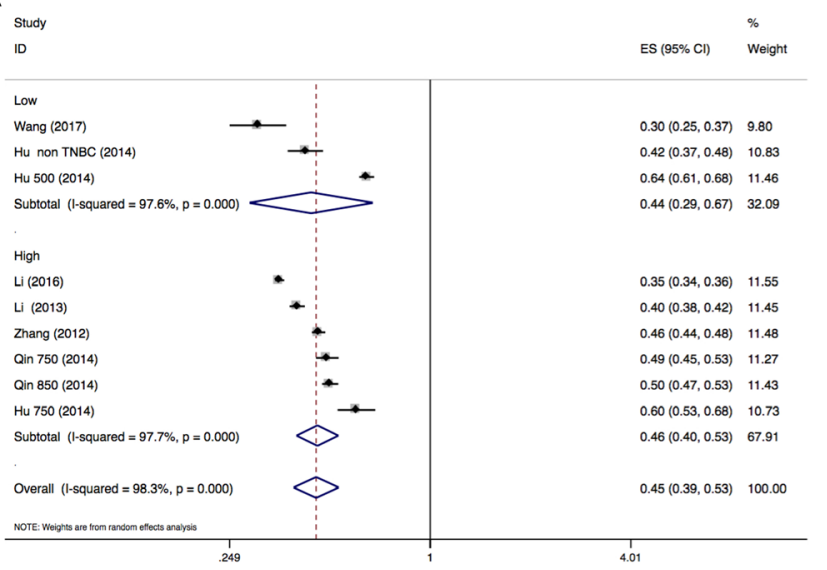

C

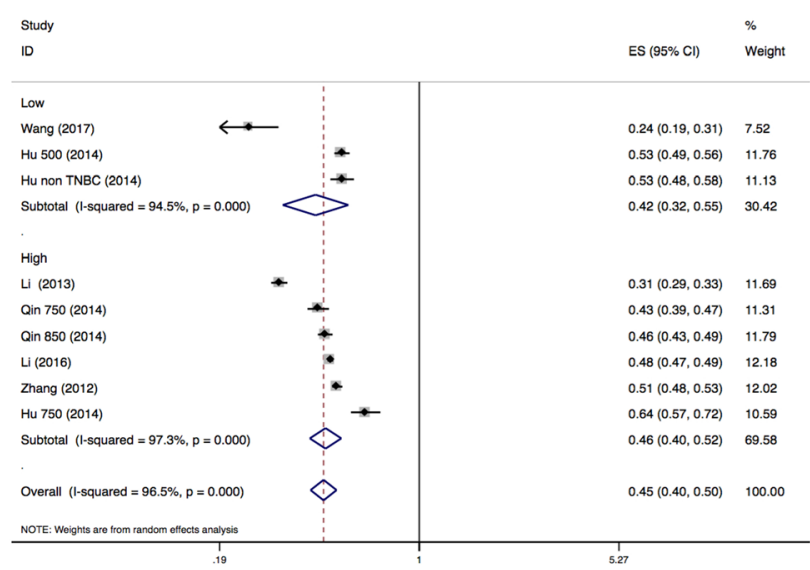

E

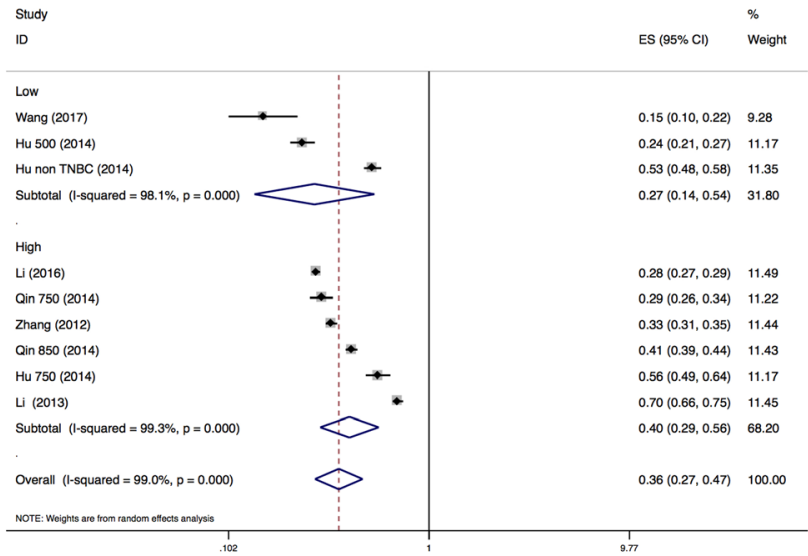

risks of developing high-grade hypertension and HFS, but not proteinuria. The overall incidence of all-grade and high-grade hypertension, proteinuria, and HFS were summarized in the present meta-analysis. The relative risks of all-grade hypertension, proteinuria and HFS were significantly increased for 6-, 2-, and 11-fold, respectively.

B

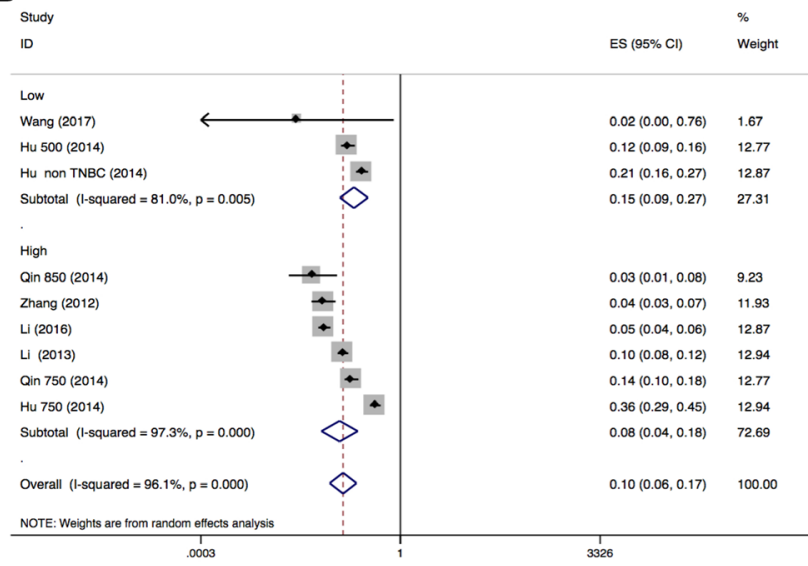

D

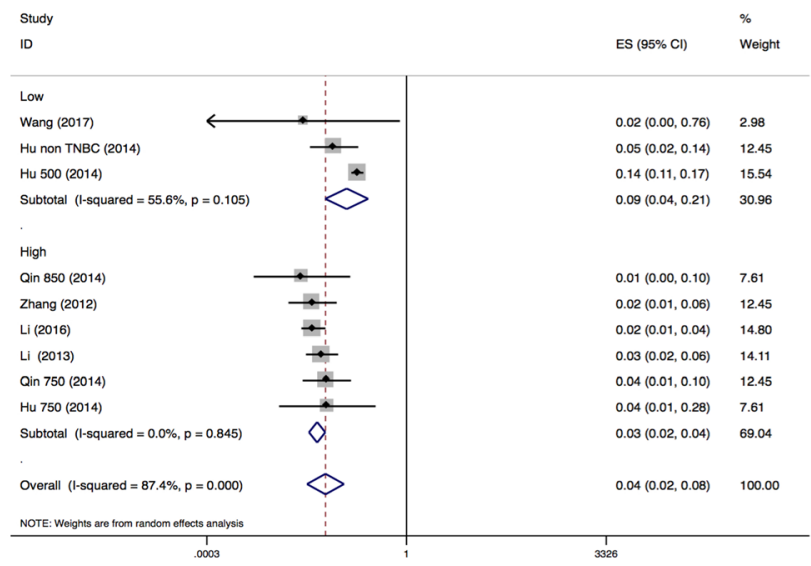

$\mathbf{F}$

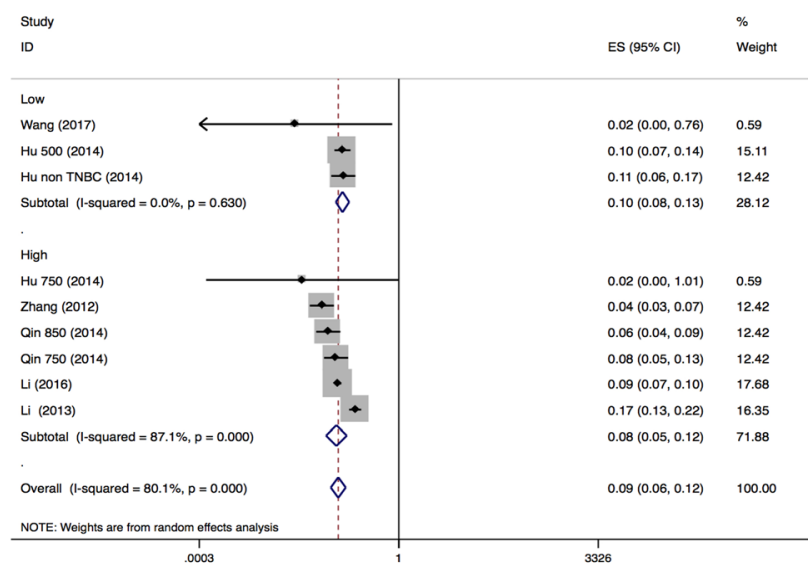

Figure 2: Forest plot for meta-analysis of incidence of all-grade and high-grade hypertension, proteinuria and HFS (dose subgroup). Each study was shown by the name of the lead author and year of publication. The summary incidence was also shown in the figure. Plots are arranged as follows: (A) Incidence of all-grade hypertension; (B) Incidence of high-grade hypertension. (C) Incidence of allgrade proteinuria; (D) Incidence of high-grade proteinuria. (E) Incidence of all-grade HFS; (F) Incidence of high-grade HFS. 
As for high-grade toxicities, compared with placebo, apatinib had 7-fold risk of developing hypertension and HFS, but not proteinuria. The confidence interval generated from the forest plot (Figure 2 and Figure 3 ) indicated the relatively small sample size of this meta- analysis. Therefore, larger randomised clinical trials are warranted to reach firm conclusion. Since single agent is sufficiently effective, combination therapy are the solution to improve the outcome. At present, several clinical trials are undertaking to combine apatinib with chemotherapy,
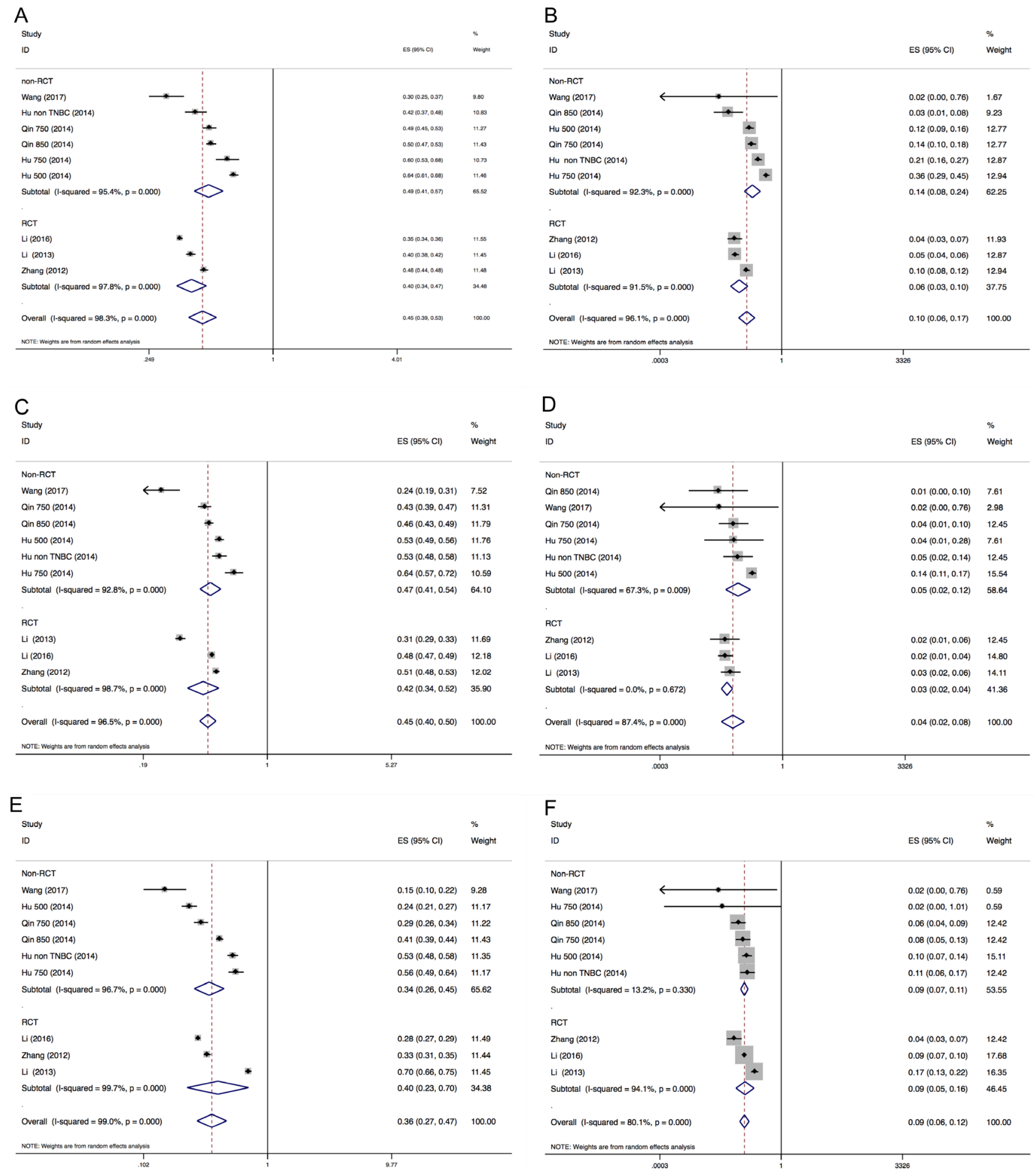

Figure 3: Forest plot for meta-analysis of incidence of all-grade and high-grade hypertension, proteinuria and HFS (research type subgroup). Each study was shown by the name of the lead author and year of publication. The summary incidence was also shown in the figure. Plots are arranged as follows: (A) Incidence of all-grade hypertension; (B) Incidence of high-grade hypertension. (C) Incidence of all-grade proteinuria; (D) Incidence of high-grade proteinuria. (E) Incidence of all-grade HFS; (F) Incidence of high-grade HFS. 
immunotherapy and other anti-neoplastic drugs. A phase 4 clinical trial is undergoing to assess the safety and efficacy of apatinib in patients with chemo-refractory gastric cancer in clinical practice (NCT02426034).

These toxicities were also reported in other multikinase inhibitors, such as sorafenib [11], sunitinib [12], pazopanib [13, 14], axitinib [15, 16], and regorafenib $[17,18]$, etc. Our finding is consistent with other antiangiogenesis drugs. VEGF plays an important part in regulating glomerular vascular permeability. Inhibition of VEGF-dependent interactions between podocytes and glomerular endothelial cells disrupts the filtration barrier, which results in proteinuria [19]. The development
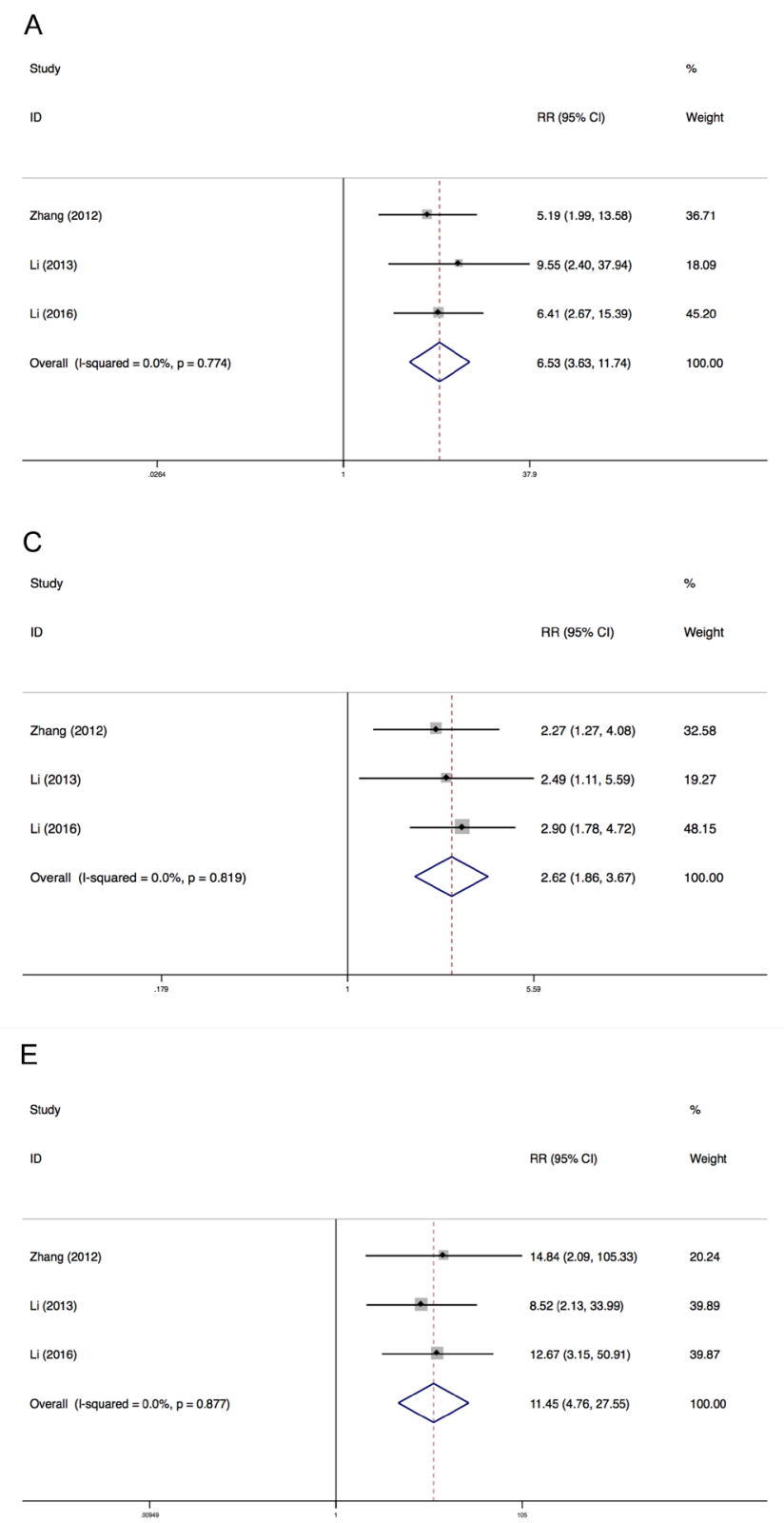

of hypertension is thought be an on-target effect of the VEGF inhibitor; therefore, it could be considered as a potential predictive factor of oncologic response [20, 21]. The development of HFS appears to correlate with dose escalations of the multikinase drug, which suggests that this may be due to a direct mechanism-based effect [22] Early onset adverse effects of apatinib is reported to be predictive of its efficacy [23], which highlighted the importance of ensuring efficacy and maintaining QoL at the same time.

Our meta-analysis demonstrates that apatinibassociated major toxicities are mostly grade 1 and 2 . The manufacturer instruction of apatinib recommends

\section{B}

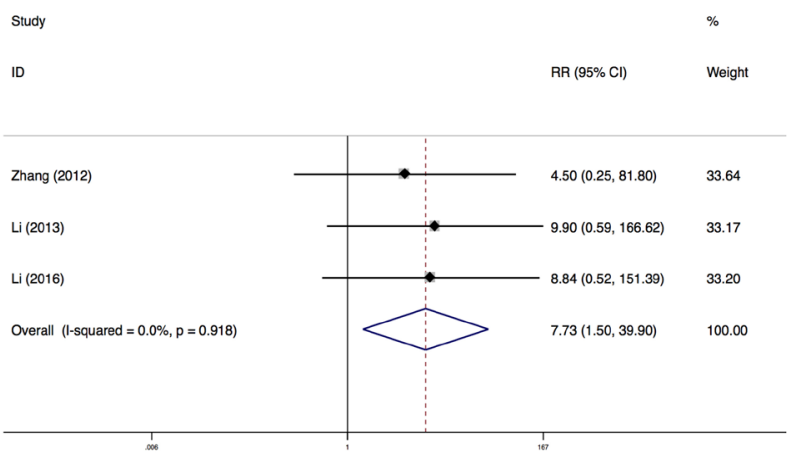

D

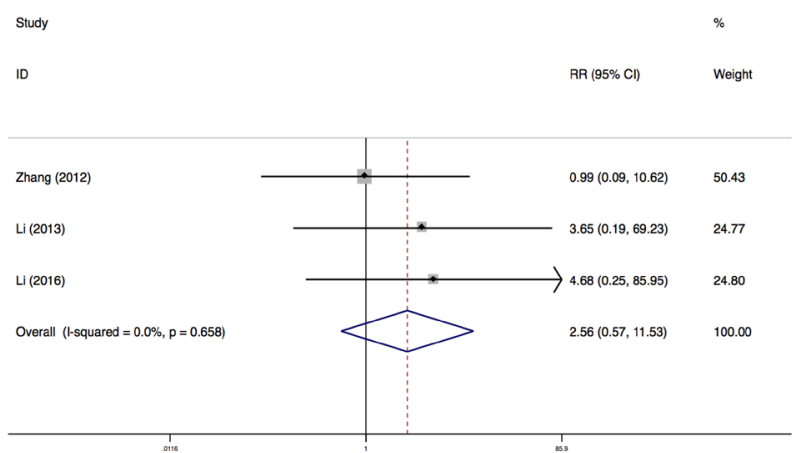

$\mathrm{F}$

Study

ID

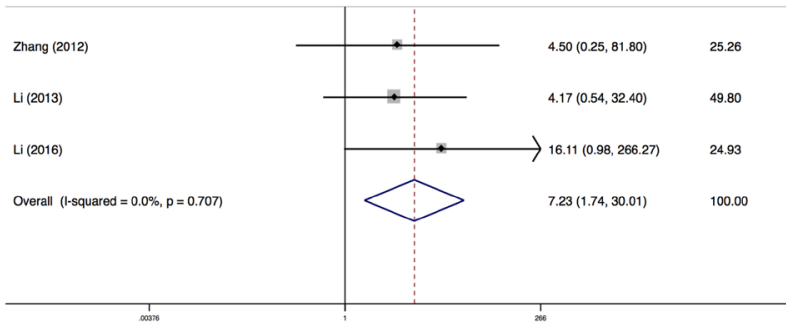

Figure 4: Relative risks of all-grade and high-grade hypertension, proteinuria and HFS. Each study was shown by the name of the lead author and year of publication. Plots are arranged as follows: (A) Relative risk of all-grade hypertension; (B) Relative risk of high-grade hypertension. (C) Relative risk of all-grade proteinuria; (D) Relative risk of high-grade proteinuria. (E) Relative risk of all-grade HFS; (F) Relative risk of high-grade HFS. 
monitoring for adverse events. For patients with highgrade hypertension, proteinuria and HFS, apatinib should be discontinued. If symptoms relieved within 2 weeks, then the original dose can be administered when adverse event dropped to below grade 2. If the adverse events continued for more than 2 weeks, dose reduction was recommended.

Our meta-analysis is not without limitations. First, the included studies were conducted with various types of cancer patients in different centers, which may have

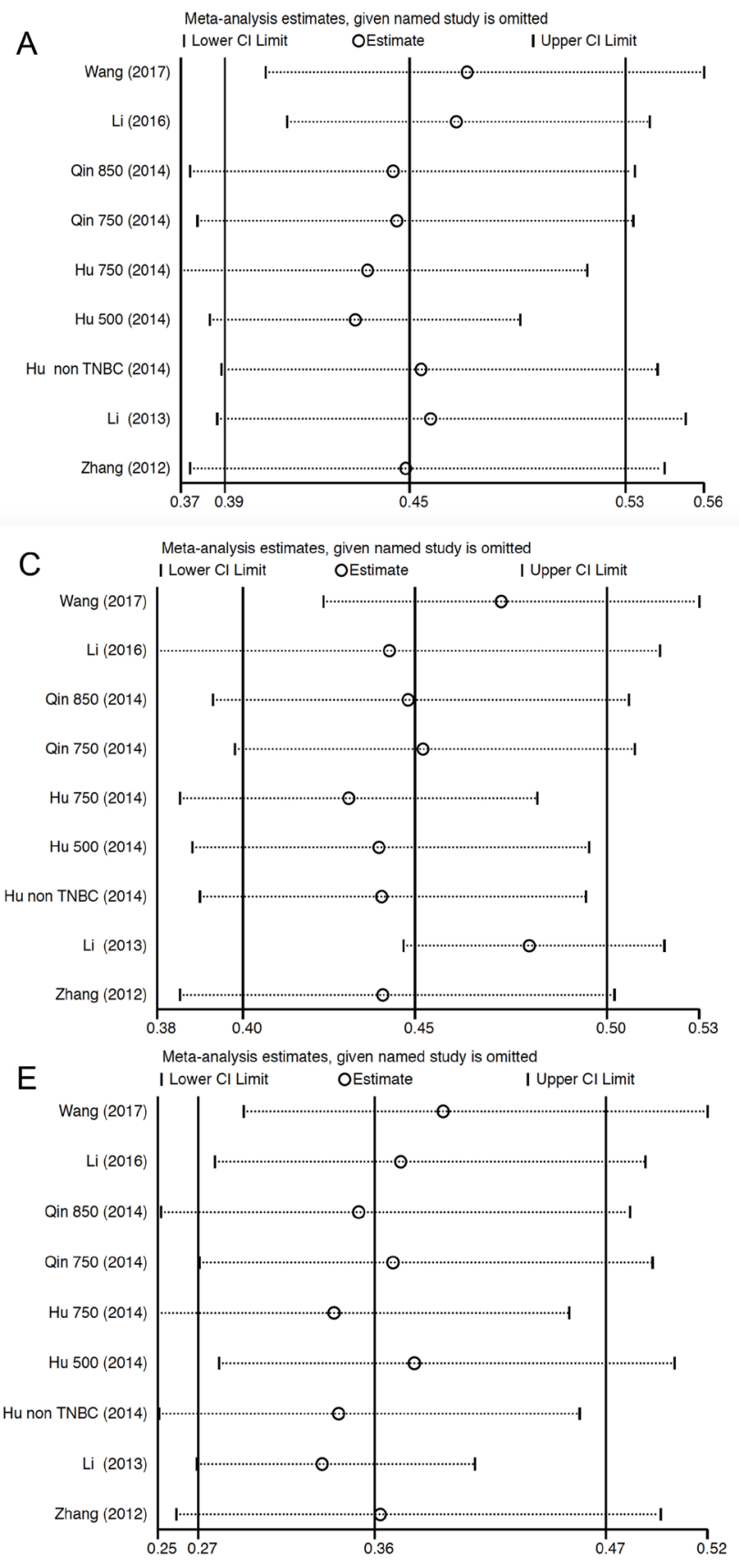

potential bias in recording adverse events. Secondly, the dose of apatinib used in clinical trial varied from trial to trial, and the dose reduction of apatinib were allowed in clinical trials, which may interfere with the results. Thirdly, there was heterogeneity among primary studies regarding small sample size and the limited primary studies.

Despite the above limitations, our meta-analysis is the first one to systematically study the incidence and relative risk of hypertension, proteinuria and HFS
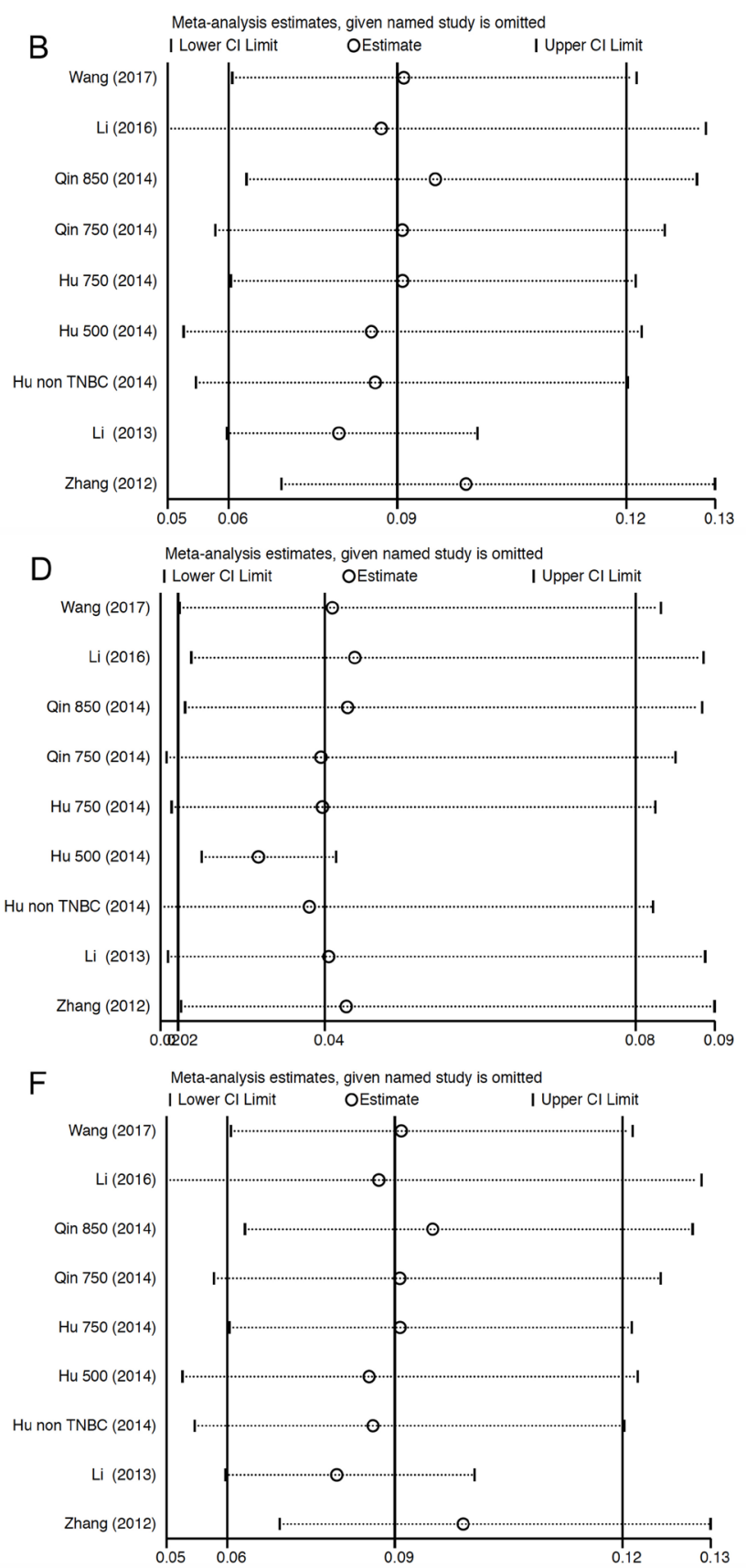

Figure 5: Sensitivity analysis for studies included in the meta-analysis for analysis of relative risk. Plots are arranged as follows: (A) Sensitivity analysis of incidence of all-grade hypertension; (B) Sensitivity analysis of incidence of high-grade hypertension. (C) Sensitivity analysis of $\mathrm{i}$ of all-grade proteinuria; (D) Sensitivity analysis of incidence of high-grade proteinuria. (E) Sensitivity analysis of incidence of all-grade HFS; (F) Sensitivity analysis of incidence of high-grade HFS. 
associated with apatinib in cancer patients. These toxicities were modest and manageable, and the results would provide important information for clinicians.

\section{MATERIALS AND METHODS}

\section{Search strategy and study selection}

Databases of PubMed, Embase, and Cochrane were searched for relevant studies (up to June 2017). Abstracts presented at ASCO annual meetings were also searched. Search terms include: ("apatinib", OR "YN968D1") And ("cancer", OR "carcinoma", OR "sarcoma"), And ("clinical trial"). Apatinib was approved for previously treated gastric cancer patients with at a recommended dose of $850 \mathrm{mg}$ QD by Chinese FDA. Clinical trials using apatinib at different doses were included in the study to assess the incidence and relative risk with these treatments.

Relevant studies that met the following criteria were included: (1) prospective phase II and III clinical trials in cancer patients; (2) participants assigned to single agent apatinib; (3) the search was restricted to clinical trial published in English; (4) events or event rate and sample size available for hypertension, proteinuria, and HFS, and (5) if multiple publications of the same trial were retrieved, only the most informative one was included. Trials with relatively small number of patients (less than 20) were excluded. Abstracts were read by two authors (LP and XY) independently. Articles that could not be determined based on title and abstract were reviewed of full-text.

\section{Study selection}

Data abstraction was conducted by two investigators (LP and XY) independently. Toxicity profile including hypertension, proteinuria and hand-foot-syndrome was extracted from the primary study. These clinical end points were recorded according to versions 4.0 of the Common Terminology Criteria for Adverse Events of National Cancer Institute (NCI-CTCAE). We included all incidences of hypertension, proteinuria and hand-footsyndrome of grade 1 or above in our analysis.

\section{Data analysis}

Information was retrieved from the primary studies, including the following items: publication year, first author, cancer type, clinical trial phase, sample size, treatment arm, and control arm. Toxicity data of all-grade and high-grade (grade 3/4) of hypertension, proteinuria, and HFS and the number of patients receiving apatinib were extracted. We derived the proportion and calculated the $95 \%$ CI of patients with hypertension, proteinuria, and HFS from each study. To calculate the summary incidence, we used an inverse variance statistical method. For controlled studies, we calculated and compared the
RRs. For one study that reported zero event in control arm, half-integer correction was used [24].

The $\chi^{2}$-based $Q$ statistic was used to calculate the heterogeneity between selected studies [25]. Heterogeneity was considered to be statistically significant if $P<0.10$ or $I^{2}>50 \%$. If heterogeneity existed, data were analyzed using a random-effects model, otherwise, a fixed-effects model was used.

A two-sided $P$ value of $<0.05$ was considered statistically significant. The presence of publication bias was evaluated by using the Begg's and Egger's tests $[26,27]$. To assess the stability of results, we performed sensitivity analysis by sequential omission of individual study. All of the calculations were performed by STATA version 14.0 (Stata Corporation, College Station, TX).

\section{ACKNOWLEDGMENTS} studies.

We are indebted to the authors of the primary

\section{CONFLICTS OF INTEREST}

None.

\section{REFERENCES}

1. Li J, Zhao X, Chen L, Guo H, Lv F, Jia K, Yv K, Wang F, Li C, Qian J, Zheng C, Zuo Y. Safety and pharmacokinetics of novel selective vascular endothelial growth factor receptor-2 inhibitor YN968D1 in patients with advanced malignancies. BMC Cancer. 2010; 10:529. https://doi.org/10.1186/1471-2407-10-529.

2. Li J, Qin S, Xu J, Xiong J, Wu C, Bai Y, Liu W, Tong J, Liu Y, Xu R, Wang Z, Wang Q, Ouyang X, et al. Randomized, Double-Blind, Placebo-Controlled Phase III Trial of Apatinib in Patients With Chemotherapy-Refractory Advanced or Metastatic Adenocarcinoma of the Stomach or Gastroesophageal Junction. J Clin Oncol. 2016; 34:144854. https://doi.org/10.1200/JCO.2015.63.5995.

3. Li J, Qin S, Xu J, Guo W, Xiong J, Bai Y, Sun G, Yang Y, Wang L, Xu N, Cheng Y, Wang Z, Zheng L, et al. Apatinib for chemotherapy-refractory advanced metastatic gastric cancer: results from a randomized, placebo-controlled, parallel-arm, phase II trial. J Clin Oncol. 2013; 31:3219-25. https://doi.org/10.1200/JCO.2013.48.8585.

4. Zang L, Shi MQ, Huang C, Liu XQ, Xiong JP, Chen GY, Liu W, Liu WC, Zhang YP, Li K, Yu H, Jiang HY. A phase II, multicenter, placebo-controlled trial of apatinib in patients with advanced nonsquamous non-small cell lung cancer (NSCLC) after two previous treatment regimens. Journal of Clinical Oncology. 2012; 30:7548.

5. Wang SY, Liu Z, Ou W, Li N, Wu HQ, Mao XY, Yuan C. Apatinib monotherapy for advanced non-small cell lung cancer after the failure of chemotherapy or other targeted therapy. J Clin Oncol. 2017; e20626-e. 
6. Hu X, Cao J, Hu W, Wu C, Pan Y, Cai L, Tong Z, Wang S, Li J, Wang Z, Wang B, Chen X, Yu H. Multicenter phase II study of apatinib in non-triple-negative metastatic breast cancer. BMC Cancer. 2014; 14:820. https://doi.org/10.1186/1471-2407-14-820.

7. Hu X, Zhang J, Xu B, Jiang Z, Ragaz J, Tong Z, Zhang Q, Wang X, Feng J, Pang D, Fan M, Li J, Wang B, et al. Multicenter phase II study of apatinib, a novel VEGFR inhibitor in heavily pretreated patients with metastatic triple-negative breast cancer. Int J Cancer. 2014; 135:19619. https://doi.org/10.1002/ijc.28829.

8. Qin S. Apatinib in Chinese patients with advanced hepatocellular carcinoma: A phase II randomized, openlabel trial. Journal of Clinical Oncology. 2014; 32:4019.

9. Moher D, Liberati A, Tetzlaff J, Altman DG. Preferred reporting items for systematic reviews and meta-analyses: the PRISMA statement. PLoS Med. 2009; 6:e1000097.

10. Holmes K, Roberts OL, Thomas AM, Cross MJ. Vascular endothelial growth factor receptor-2: structure, function, intracellular signalling and therapeutic inhibition. Cell Signal. 2007; 19:2003-12. https://doi.org/10.1016/j.cellsig.2007.05.013.

11. Wu S, Chen JJ, Kudelka A, Lu J, Zhu X. Incidence and risk of hypertension with sorafenib in patients with cancer: a systematic review and meta-analysis. Lancet Oncol. 2008; 9:117-23. https://doi.org/10.1016/S1470-2045(08)70003-2.

12. Zhu X, Stergiopoulos K, Wu S. Risk of hypertension and renal dysfunction with an angiogenesis inhibitor sunitinib: systematic review and meta-analysis. Acta Oncol. 2009; 48:9-17. https://doi.org/10.1080/02841860802314720.

13. Qi WX, Lin F, Sun YJ, Tang LN, He AN, Yao Y, Shen Z. Incidence and risk of hypertension with pazopanib in patients with cancer: a meta-analysis. Cancer Chemother Pharmacol. 2013; 71:431-9. https://doi.org/10.1007/s00280-012-2025-5.

14. Balagula Y, Wu S, Su X, Feldman DR, Lacouture ME. The risk of hand foot skin reaction to pazopanib, a novel multikinase inhibitor: a systematic review of literature and meta-analysis. Invest New Drugs. 2012; 30:1773-81. https://doi.org/10.1007/s10637-011-9652-2.

15. Fischer A, Wu S, Ho AL, Lacouture ME. The risk of hand-foot skin reaction to axitinib, a novel VEGF inhibitor: a systematic review of literature and meta-analysis. Invest New Drugs. 2013; 31:787-97. https://doi.org/10.1007/s10637-013-9927-x.

16. Qi WX, He AN, Shen Z, Yao Y. Incidence and risk of hypertension with a novel multi-targeted kinase inhibitor axitinib in cancer patients: a systematic review and meta-analysis. Br J Clin Pharmacol. 2013; 76:348-57. https://doi.org/10.1111/bcp.12149.
17. Belum VR, Wu S, Lacouture ME. Risk of hand-foot skin reaction with the novel multikinase inhibitor regorafenib: a meta-analysis. Invest New Drugs. 2013; 31:1078-86. https://doi.org/10.1007/s10637-013-9977-0.

18. Wang Z, Xu J, Nie W, Huang G, Tang J, Guan X. Risk of hypertension with regorafenib in cancer patients: a systematic review and meta-analysis. Eur J Clin Pharmacol. 2014; 70:225-31. https://doi.org/10.1007/s00228-013-1598-1.

19. Eremina V, Sood M, Haigh J, Nagy A, Lajoie G, Ferrara N, Gerber HP, Kikkawa Y, Miner JH, Quaggin SE. Glomerularspecific alterations of VEGF-A expression lead to distinct congenital and acquired renal diseases. J Clin Invest. 2003; 111:707-16.

20. Rixe O, Billemont B, Izzedine H. Hypertension as a predictive factor of Sunitinib activity. Ann Oncol. 2007; 18:1117. https://doi.org/10.1093/annonc/mdm184.

21. Estfan B, Byrne M, Kim R. Sorafenib in advanced hepatocellular carcinoma: hypertension as a potential surrogate marker for efficacy. Am J Clin Oncol. 2013; 36:319-24. https://doi.org/10.1097/COC.0b013e3182468039.

22. Strumberg D, Awada A, Hirte H, Clark JW, Seeber S, Piccart P, Hofstra E, Voliotis D, Christensen O, Brueckner A, Schwartz B. Pooled safety analysis of BAY 43-9006 (sorafenib) monotherapy in patients with advanced solid tumours: Is rash associated with treatment outcome? Eur J Cancer. 2006; 42:548-56. https://doi.org/10.1016/j.ejca.2005.11.014.

23. Liu XY, Qin SK, Wang ZX, Xu JM, Xiong JP, Bai YX, Wang ZH, Yang Y. Early presence of antiangiogenesisrelated adverse events as a potential biomarker of antitumor efficacy in patients with metastatic gastric cancer treated with apatinib. J Clin Oncol. 2017; 10:153.

24. Choueiri TK, Schutz FA, Je Y, Rosenberg JE, Bellmunt J. Risk of arterial thromboembolic events with sunitinib and sorafenib: a systematic review and meta-analysis of clinical trials. J Clin Oncol. 2010; 28:2280-5.

25. Zintzaras E, Ioannidis JP. Heterogeneity testing in metaanalysis of genome searches. Genet Epidemiol. 2005; 28:123-37.

26. Yusuf S, Peto R, Lewis J, Collins R, Sleight P. Beta blockade during and after myocardial infarction: an overview of the randomized trials. Prog Cardiovasc Dis. 1985; 27:335-71.

27. Begg CB, Mazumdar M. Operating characteristics of a rank correlation test for publication bias. Biometrics. 1994; 50:1088-101. 